\title{
DISPARITY IN PERFORMANCE OF THE CZECH CONSTRUCTION SECTOR: EVIDENCE FROM THE MARKOV-SWITCHING MODEL
}

\author{
Václav Adamec ${ }^{1}$ \\ ${ }^{1}$ Department of Statistics and Operations Research, School of Business and Economics, Mendel University in \\ Brno, Zemědělská 1, 61300 Brno, Czech Republic
}

To cite this article: ADAMEC VÁCLAV. 2018. Disparity in Performance of the Czech Construction Sector: Evidence from the Markov-Switching Model. Acta Universitatis Agriculturae et Silviculturae Mendelianae Brunensis, 66(6): 1383-1391.

To link to this article: https://doi.org/10.11118/actaun201866061383

\begin{abstract}
Activities in the construction sector are assumed to be influenced by inflow of mortgage funding in the private housing sector and public finances targeted at large infrastructure projects, apart from climate variables. In this study, we modeled seasonal time series representing monthly output in the Czech construction sector in CZK mil. during 2000:1 through 2016:12 (T=204) adjusted for calendar variations and seasonal movements via TRAMO-SEATS and then transformed to natural logarithms of gross returns. A Markov-Switching model with two states, no intercept, average monthly temperature, average monthly precipitation and parameters of first-order autoregression process was specified and estimated by the Expectation-Maximization. In State 1 of regular performance, the log-differenced returns were significantly and positively influenced by precipitation levels, but not by ambient outdoor temperature. In State 2 of non-standard operation of the construction sector, the transformed series was unaffected by precipitation levels, but instead by ambient outdoor temperatures. First-order autocorrelation dependency in both regimes was established. Changes in legal and macroeconomic environment pertinent to tax law amendments affecting VAT or corporate tax, country's accession to EU or large construction project deadlines were shown to induce nonstandard regime in the construction sector (State 2). The model classified $91 \%$ observations in the first state, while only $9 \%$ data belonged to the State 2 . Transition probability matrix indicates that change from model State 1 to State 2 is difficult to attain. At the same time, once State 2 was established, it tends to persist or change to State 1 with near equal probability. Ability of the Markov-Switching model to identify both states is reasonably good.
\end{abstract}

Keywords: construction sector, TRAMO-SEATS, Markov-Switching model, Value Added Tax, corporate tax, transition probability, $R$-software

\section{INTRODUCTION}

Since the Velvet Revolution in 1989, the Czech Republic's economy underwent a period of lengthy economic and social transformation. It has brought a radical change of property ownership from ambient state before 1989 to prevailing private at present, which later lead to continuing improvements in efficiency, quality, technology improvements and economic productivity. During this period, the country's construction sector has been liberalized and many small to medium sized construction companies appeared. The main goal of the sector was to participate in building and reconstruction of the country infrastructure, such as pipes, highways, roads and railways, 
construction of new plants, shopping centers and last, but not least, securing modern and affordable housing for the ever more affluent population. The construction sector thus became essential part of the Czech economy, employing in excess of 300 thousand and contributing around $7 \%$ to the overall economic output (GDP). After 2007, the share of the construction sector to GDP however shows mild, but declining trend. Mitrenga and Bělohlávek (2017) report that investments in the construction sector lead to 2.2 to 2.3 times multiplication effect in the economy. Monitoring of the construction sector performance therefore receives attention of the private companies as well as the public authorities.

Construction activity shows moderate to sizeable differences among regions of the country. Most construction work is concentrated in the Prague area and the Středočeský region, followed by regions Jihomoravský (Brno and surrounding area) and Moravskoslezský (Ostrava and vicinity). Generally, substantial construction work occurs in areas close to all regional cities, except Ústí nad Labem, where mountainous terrain and economic shortage hinder the appearance of new and well-funded construction projects. On the other hand, low construction activity can be found in regions Zlínský, Liberecký and Karlovarský due to low population density and small geographical size. Most small to medium size construction companies favor accepting work on construction projects in the same region of the company residence or in the neighboring regions to save costs. In general, tapping small projects in distant regions appears less profitable and therefore many companies avoid it (Cuřinová, 2016).

In 2008-2009, the onset of the economic and financial crisis caused a considerable slowdown of the Czech economy. It was accompanied by a reduction of activities in the construction sector due to shortage of mortgage funding in the private housing segment and deceleration of the flow of public finances earmarked for large infrastructure projects, as a result of austerity measures adopted by the government. New project freezing, delays or conservation of ongoing construction projects followed until 2012, when a new round of government infrastructure projects appeared after having received proper attention and also due to assistance of EU funds. Nonetheless, until now the construction sector output has not reached its former peak levels witnessed during 2008-2009. A principal motivation for exploring dynamics of the performance in the construction sector was a series of macroeconomic events occurring during 2000-2016 that could be hypothesized to exert influence upon the construction sector's output. Potentially, these include changes to the tax code, primarily VAT, alterations of the macroeconomic environment due to the country's accession to EU, phase of economic cycle, schedule and timing of EU funding periods and government austerity measures launched to preserve long term fiscal stability. It is therefore expected that quantitative descriptions and understanding of the forces behind the construction sector's performance may be helpful to minimize unfavorable volatility in the sector output and confine movements associated with the economic cycle. Findings of this study could be of assistance to managers of the large construction companies, local government authorities and managers of the large infrastructure projects funded partially by the EU structural funds.

Modeling dynamic relationships between construction time series and other variables requires formulation of several assumptions. Foremost, the raw data is deemed stochastic with strong calendar influences, non-seasonal and seasonal autocorrelations and external influences due to climate variables. Also, we believe that two distinct states of the construction series exist, standard operation and nonstandard, each with specific parameters, assuming unequal behavior of the data generating process between the states. The objective of this study is to characterize and quantitatively describe the stochastic process that generates the data in the two regimes, apart from external climate and random elements. The paper thus brings novel information and insight into the character of dependencies among the serially correlated data, impact of external weather variables and volatility of the output growth. The quantification of the construction output dependency upon climate could be especially valuable, since some construction technologies cannot be applied in all weather. Finally, the paper aims to provide dating of the respective regimes under stochastic conditions. To fulfill the objectives, a two-state Markov Switching model is proposed and fitted. Further, tabulated and graphical information is supplied to support the conclusions formulated therefrom.

\section{MATERIALS AND METHODS}

At the beginning, it is supposed for the proposed investigation, that construction time series is stochastic but mutually correlated with invariable time lag. Also, it is expected that output of the construction sector shows strong seasonal component thus implying dependency upon ambient outdoor temperatures, levels of precipitations, dates of seasonal holidays and periods of work leave, that occur primarily in the summer or during Christmas and New Year holidays. The data, as a result, is expected to be seasonally auto-correlated. Furthermore, there is strong evidence, that construction sector's performance is affected by number of days or workdays per month; level of economic activity associated with economic cycle, such as number, size and price of construction demand. The construction sector is known to be strongly influenced by public 
expenditures in infrastructure and it acts as early indicator of the investment sentiment in the Czech economy. It is the construction sector activity that exhibits early signs of the incoming economic recovery and frequently helps generate abundant employment opportunities for the low to medium qualified labor, both domestic and foreign.

Data in this study constitute monthly time series representing monetary value of the Czech construction sector output assessed at current prices (CZK mil.) and covering the 17-year period 2000:1 to 2016:12 (T=204). The numerical observations were calculated from year-on-year indices commonly published by the Czech Statistical Office (www.czso.cz) and value data available at the CZSO before 2010. Since the monthly observations of the construction output were influenced by calendar variations, the data were standardized to the average level 30.42 days per month and then seasonally adjusted by the method of TRAMO-SEATS devised by Maravall and Caporello (1996) at the Bank of Spain. Since the Fisher test (Brockwell and Davis, 1991) detected significant periodic component with 12-month frequency $(p<0.01)$ in the raw construction output data, R-library seasonal (Sax, 2016) was applied for the seasonal adjustments. Due to occurrence of non-stationarity, the season-adjusted data were transformed to the stationary first-order differenced natural logarithms of gross returns $\ln k_{t}=\ln y_{t}-\ln y_{t-1}$, where $k_{t}=y_{t} / y_{t-1}$ are chain indices for. This transformation has the benefit that assuming the distribution of $t=2,3, \ldots, T$ is log-normal, the distribution of the natural logarithms of $k_{t}$ is normal.

Stationarity of the log-differenced series was later checked via Augmented Dickey-Fuller (1981) test. Diagrams of the unadjusted, calendar and seasonally adjusted construction data and corresponding log differences are shown in Fig. 1. Weather related data were obtained from the historical data portal of the Czech Institute of Hydrology and Meteorology (http://portal.chmi.cz/), a public institution responsible for collecting and analyzing weather related records and providing official weather forecasts in the Czech Republic. The variables of interest include average monthly temperature $\left({ }^{\circ} \mathrm{C}\right)$ and precipitation $\left(\mathrm{mm} \cdot \mathrm{m}^{-2}\right)$ series connected to the country's territory. The weather records were later seasonally adjusted via TRAMO-SEATS, because occurrence of seasonal patterns was expected and later verified by the Fisher test for periodic component (Brockwell and Davis, 1991). Since the data provider averaged mean precipitations per $\mathrm{m}^{2}$ data only geographically, the records were also adjusted for calendar day variations. Assumptions of calendar day variations in temperature data could not be justified and, for this reason, calendar adjustment of this series was deemed redundant. Fig. 2 shows raw weather data and calendar and season adjusted records with time trend in temperatures and precipitations added. Transformed data were then smoothed with 12-month centered, two-sided linear convolution filter. Stationarity of the transformed data was verified with the Augmented Dickey-Fuller (1981)
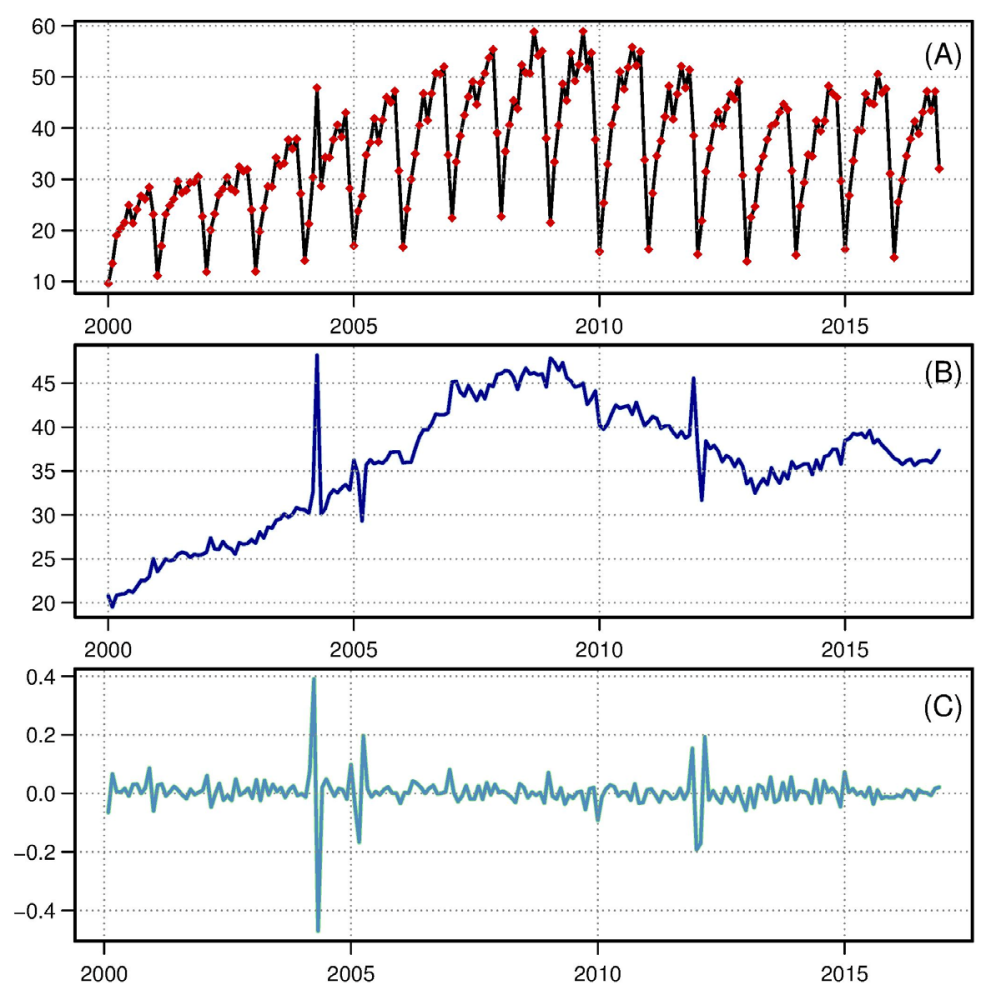

1: Diagram of the original data (A), calendar and season adjusted data (B) and log differenced adjusted data (C). 
test with deterministic components time trend, level constant or missing constant and lag of autocorrelation in residuals selected by the AIC criterion. The correct variant of the ADF test for unit root was finally chosen based on significance tests of the deterministic components.

Autocorrelation structure of the transformed construction output was explored via plots of autocorrelation (ACF) and partial autocorrelation function (PACF). The diagrams indicated significant 1-st order serial correlations in the log returns and later resulted in autoregression term added to the Markov-Switching model (Hamilton, 1990). Initial fixed effect linear model can be generally described by the equation

$$
\Delta \ln Y_{t}=\beta_{0}+\beta_{1} \Delta Z_{t}+\beta_{2} \Delta W_{t}+\varepsilon_{t},
$$

where $\Delta \ln Y_{t}$ is $\log$-differenced monthly output of the construction sector adjusted for seasonal and calendar variations; $\beta_{0}$ is level constant; $Z_{t}$ is the season-adjusted mean monthly temperature; $W_{t}$ is the season and calendar adjusted mean monthly precipitations and $\varepsilon_{t}$ is a stochastic error term. The specification of the exogenous variables is done uniformly for all equations, conditional on parameter significance in any equation. Now, let us assume Markov Switching process with two regimes $(r=2)$; the transformed response variable then follows Gaussian distribution
$\Delta \ln Y_{t} \sim\left\{\begin{array}{l}N\left(X \beta, \sigma_{1}^{2}\right) \\ N\left(X \beta^{*}, \sigma_{2}^{2}\right)\end{array}\right.$,

in States 1 and 2, respectively, depending on the unobserved variable $D_{t}$ taking one of two discrete values $D_{t}=1$ or $D_{t}=2$.

In the regimes, the conditional expectations and variances are allowed to differ. Since $D_{t}$ is unobserved and follows 1-st order Markov chain, the probability that regime $D_{t}=i$ holds for observation at time $t$, depends on the regime at time $t-1, D_{t-1}=j$. Links of the observation to regimes cannot be decided exactly, however with probability $p \in[0,1]$ (Arlt and Arltová, 2007). As a result, conditional probability $p_{i j}=P\left(D_{t}=i \mid D_{t-1}=j\right)$ is introduced and stored in so-called transition probability matrix

$P=\left[\begin{array}{ll}p_{11} & p_{12} \\ p_{21} & p_{22}\end{array}\right]$,

where only the diagonal elements $p_{11}$ and $p_{22}$ have to be estimated, since $\sum p_{i}=1$, for given $j$. Calculations of the marginal probabilities of the model being in regime 1 or regime 2 were reported by Hamilton (1994)

$P\left(D_{t}=1\right)=\frac{1-p_{22}}{2-p_{11}-p_{22}}$
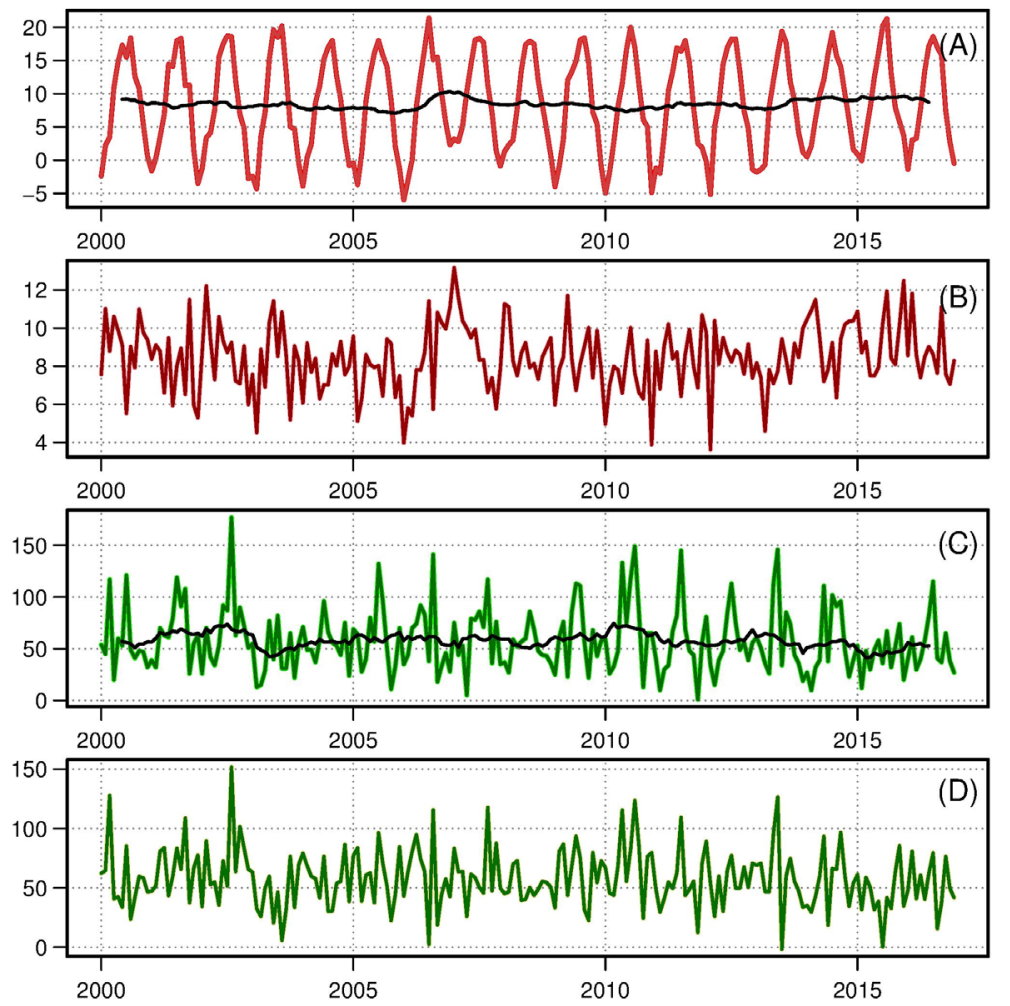

2: Line diagrams of the average monthly climate data: unadjusted temperatures with 12-month linear convolution filter (A); season adjusted temperatures (B); unadjusted precipitations with trend (C) and calendar and season-adjusted precipitations (D). 
$P\left(D_{t}=2\right)=\frac{1-p_{11}}{2-p_{11}-p_{22}}$.

Zivot and Wang (2006) provided expressions for calculating average duration of the $i$-th regime from the elements of the P matrix

$d_{i}=\frac{1}{1-p_{i i}}$.

The Markov Switching model thereby allows for separate modelling of the autocorrelation structure and external influences through distinct equations in $r$ regimes. Arlt and Arltová (2007) postulate that Markov Switching model may be hypothetically further extended to scenarios with $t>2$ regimes, however specification of regimes is primarily conditioned on the available data and the ability of the analyst to draw rational conclusions therefrom. Estimation of parameters and residual variances in regimes is secured via Expectation-Maximization (EM) algorithm of the Maximum Likelihood by Dempster et al. (1977) with starting values for the parameters chosen at random. We applied $M S w M$ extension package developed by Sanchez-Espigares and Lopez-Moreno (2014) in R-software (www.r-project.org) to obtain the estimates.

\section{RESULTS AND DISCUSSION}

Measurement frequency of the data implies that time series are likely subject to recurrent seasonal oscillations due to periodic changes in weather patters and subsequently shall display significant high order autocorrelations. Fisher test has the capability to attest significance of the largest ordinate of the periodogram (see Tab. I). It indicated a clear presence of continuing seasonal volatility in the construction, temperature and precipitation data with the period of 12 months $(p<0.001)$. The seasonal and trend decomposition of the construction data based on Lowess smoothing (Cleveland et al., 1990) gives indication,

I: Fisher tests for occurrence of periodic components.

\begin{tabular}{lccc}
\hline \multicolumn{1}{c}{ Variable } & Frequency & No cycles & P-value \\
\hline Output $^{1}$ & 12 & 17 & $<0.0001$ \\
Temperature $^{2}$ & 12 & 17 & $<0.0001$ \\
Precipitation $^{1}$ & 12 & 17 & $<0.0001$ \\
\hline
\end{tabular}

${ }^{1}$ Calendar adjusted data

${ }^{2}$ Raw unadjusted data
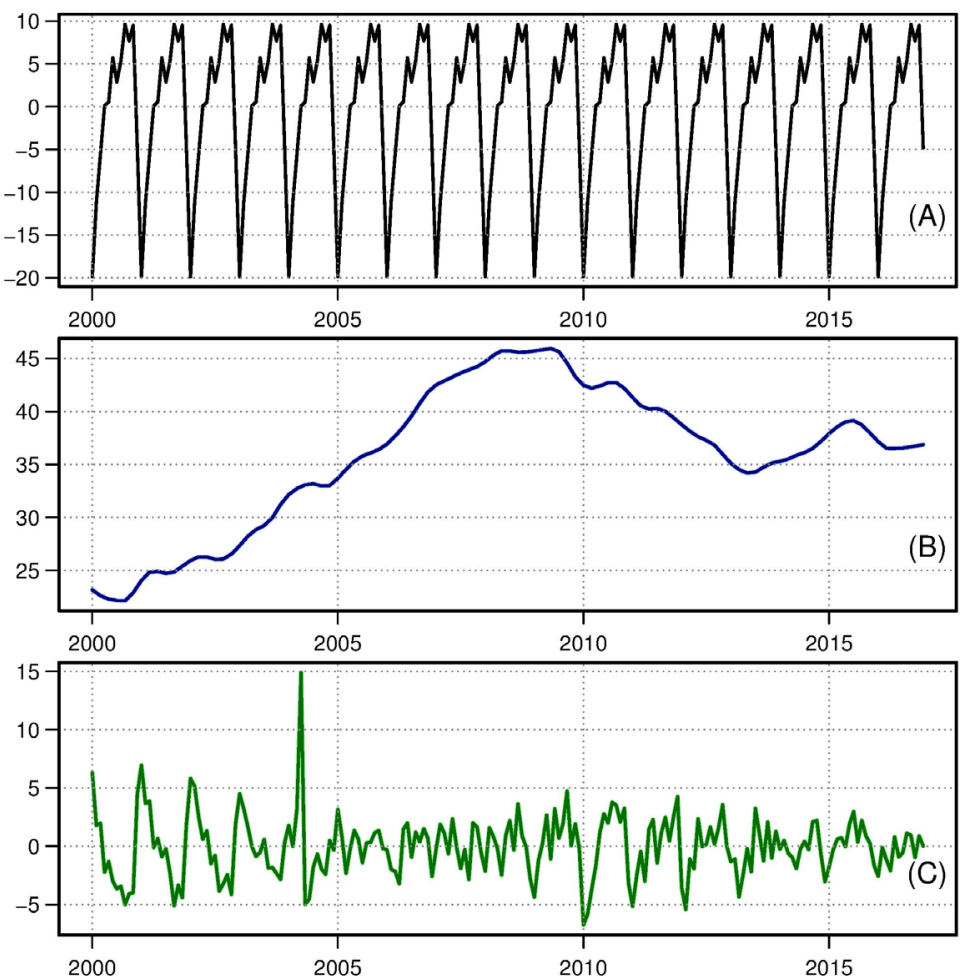

3: Lowess decomposition for trend and seasonal constituents of the unadjusted construction data: seasonal component ( $A)$, trend (B) and disturbance component (C). 
that the construction output series can be viewed as a composite of three major elements: trend, seasonal and random (Fig. 3). Non-random volatility in the error series (C) could be explained by irregularities of the seasonal patterns in time or imperfections of the smoothing method.

Line diagrams of the calendar and seasonaly adjusted construction data (see Figs. 1 and 2) indicate that we deal with integrated time series $I(1)$ with a non-seasonal unit root, because the variable increase or decrease mostly with the economic cycle. The KPSS tests (Kwiatkowski et al., 1992) not only point to non-stationarity of the construction output variable (KPSS $=2.407, p<0.01$ ), but also indicate stationarity of the differenced construction data $\quad($ KPSS $=0.2533, \quad p>0.1$ ). Subsequently, Augmented Dickey Fuller test (Dickey and Fuller, 1981) was applied to validate the null hypothesis of unit root (see Tab. II). The procedures provide firm statistical evidence that output and climate variables are stationary around the level constant or difference stationary after necessary adjustments for calendar and seasonal fluctuations. The presence of a deterministic time trend in ADF auxiliary model was tested via partial $t$-test, but no evidence of a significant linear trend was found.

Following exploratory tests and diagrams, we pursued specification and estimation of the two-state Markov-Switching model. We assumed that the first regime reflects regular construction sector performance under prevailing well-known and established conditions. It is anticipated that majority of observations belongs to the first regime. On the other hand, the second regime is thought to include observations that reflect unusual behavior of the sector output, both in the positive and negative direction. In the second regime, the observations are driven by nonstandard conditions that were induced, for example, by amendments to the tax code, political decisions, large project completions, end of calendar year or abrupt and unexpected changes of the macroeconomic environment, to which the construction companies must adopt. The Markov-Switching model was specified without the intercept, because the population mean of the dependent variable was zero $(t=0.688$, $d f=202, p=0.493)$. The model showed better fit and higher error variance in the second regime, compared to the first regime, where lower $R^{2}$ and reduced error variance occurred (see Tab. III). It indicates that magnitude of change in the second regime is frequently higher, compared to the first regime, where lower dynamics regularly takes place.

It follows from the Markov Switching model that the construction sector's output appears to be negatively influenced by the level of precipitations

II: Augmented Dickey-Fuller tests for unit root.

\begin{tabular}{|c|c|c|c|c|c|c|}
\hline Variable & Model & Lag & Slope estimate & Standard error & Test statistic & $P$-value \\
\hline Output $^{1}$ & Constant & 4 & -0.0488 & 0.0227 & -2.151 & 0.0328 \\
\hline$\Delta$ Output & No drift & 3 & -2.4621 & 0.2366 & -10.407 & $<0.0001$ \\
\hline Temperature ${ }^{2}$ & Constant & 2 & -0.6475 & 0.1069 & -6.0595 & $<0.0001$ \\
\hline$\Delta$ Temperature & No drift & 7 & -3.9515 & 0.4967 & -7.9553 & $<0.0001$ \\
\hline Precipitation $^{1}$ & Constant & 12 & -1.0488 & 0.2751 & -3.8125 & 0.0002 \\
\hline$\Delta$ Precipitation & No drift & 11 & -6.8630 & 0.8842 & -7.7622 & $<0.0001$ \\
\hline
\end{tabular}

${ }^{1}$ Calendar and season adjusted data

${ }^{2}$ Season adjusted data

III: Coefficients of the Markov-Switching model and indicators of model fit in regimes.

\begin{tabular}{cccccc}
\hline Regime & Parameter & Estimate & Std.Error & z-ratio & $p$-value \\
\hline \multirow{2}{*}{ State 1 } & $\beta_{1}$ (temperature) & 0.0007 & 0.0009 & 0.7644 & 0.4446 \\
& $\beta_{2}$ (precipitation) & -0.0002 & 0.0001 & -3.3468 & 0.0008 \\
& $\phi_{1}(\mathrm{AR}(1))$ & -0.0771 & 0.0358 & -2.1552 & 0.0311 \\
& $R_{1}^{2}=0.133$ & & $\hat{\sigma}_{1}=0.0211$ & & 0.0413 \\
\multirow{2}{*}{ State 2} & $\beta_{1}$ (temperature) & 0.0202 & 0.0099 & 2.0409 & 0.1231 \\
& $\beta_{2}$ (precipitation) & 0.0014 & 0.0009 & 1.5418 & 0.0074 \\
\hline
\end{tabular}


in the first regime. In the second regime, the rising ambient temperatures show positive partial correlation with the performance of the construction sector. In the first regime, the data show lower intensity of serial dependencies, compared to the second regime, although both autocorrelations have a negative sign. These findings correspond with author anticipations formulated prior to estimation of the Markov Switching model.

Matrix $P$ of estimated transition probabilities is given in Tab. IV. Transition probability $p_{i j}$ specifies probability of transition from regime $i$ at time $t-1$ (column) to regime $j$ at time $t$ (row). It shows that for two adjacent observations a change from regime 1 to regime 2 is difficult to attain and in that way not very likely. Nonetheless, once regime 2 was established, it shows inclination to persist or change to Regime 1 with near equal probability. Long-run marginal probabilities that the model is found in a specific regime, were received $P(D=1)=0.8784$ and $P(D=2)=0.1216$ by applying formulas (4) and (5). It follows from the transition probability matrix (see equation 6 ) that the average duration of the regime 1 of standard operation was 16.5 months and the non-standard regime 2 lasted only 2.3 months on average.

One of the interesting discoveries in this model is classification of the data observations into regimes one or two by the Markov-Switching model. In overall, 184 data points were classified into regime one of regular operation, while only 18 observations were assigned to regime two with nonstandard operation of the construction sector. Tab. V. shows tabulated timing of the data in regime two (State 2) and effective dates of changes in the Czech tax code in the period covered by the available data. This usually means either a change in the Value Added Tax (VAT) or the Corporate Tax (CT) rates. There is generally a sizeable agreement between timing of the changes in the tax code and data classification in the regime 2 . However, magnitude of changes in the tax rates varied during the period covered by the data from a single percentage point to 4 percentage points. The impact of the tax rate changes upon the output of the construction sector may have been different in specific years. For example, the Markov-Switching model did not detect a large switch of tax rates in January 2008. This could be explained by superfluous activity in the construction sector caused by the peak of the economic cycle and need to complete unfinished projects by 2007. Apart from tax changes, other influences, such as phase of the economic cycle, government investments in infrastructure and EU co-funding, also may have played a significant role. Fig. 4 shows filtered and smoothed probabilities that a specific observation is assigned to one of the regimes (States 1 or 2); further it shows dating of observations in regime two and timings of effective dates for change in the tax code, both VAT and CT. Regime 2 often occurs in the winter months, shortly before, during or immediately after the coming year and it is tied to periods of unpredictable activity in the construction sector.

IV: Estimated matrix of transition probabilities $p_{i j}$ for the Markov-Switching model.

\begin{tabular}{lcc}
\hline & State 1 & State 2 \\
\hline State 1 & 0.93956 & 0.43651 \\
State 2 & 0.06044 & 0.56349 \\
Sum & 1.00000 & 1.00000 \\
\hline
\end{tabular}

V: Data timing in the second regime (State 2), as determined by the Markov-Switching model and effective dates for changes in the Czech tax rates.

\begin{tabular}{|c|c|}
\hline Regime two dating & Timing of tax rate change \\
\hline 2000 Mar, Dec & $2000 \mathrm{Jan}^{\mathrm{st}}(\mathrm{CT})$ \\
\hline 2001 Jan & - \\
\hline $2002 \mathrm{Feb}$ & - \\
\hline 2004 Mar, Apr, May & 2004 May $1^{\text {st }}(\mathrm{VAT}, \mathrm{CT})$ \\
\hline 2005 Jan, Mar, Apr & $2005 \mathrm{Jan} 1^{\text {st }}(\mathrm{CT})$ \\
\hline- & $2006 \mathrm{Jan}^{\mathrm{st}}(\mathrm{CT})$ \\
\hline 2007 Jan & - \\
\hline- & $2008 \mathrm{Jan} 1^{\text {st }}(\mathrm{VAT}, \mathrm{CT})$ \\
\hline 2009 Jan & $2009 \mathrm{Jan} \mathrm{1}^{\text {st }}(\mathrm{CT})$ \\
\hline $2010 \mathrm{Jan}$ & $2010 \mathrm{Jan} 1^{\text {st }}(\mathrm{VAT}, \mathrm{CT})$ \\
\hline \multicolumn{2}{|l|}{2011 Dec } \\
\hline 2012 Jan, Feb, Mar & 2012 Jan $1^{\text {st }}(\mathrm{VAT})$ \\
\hline- & 2013 Jan $1^{\text {st }}(\mathrm{VAT})$ \\
\hline $2015 \mathrm{Jan}$ & 2015 Jan $1^{\text {st }}(\mathrm{VAT})$ \\
\hline
\end{tabular}



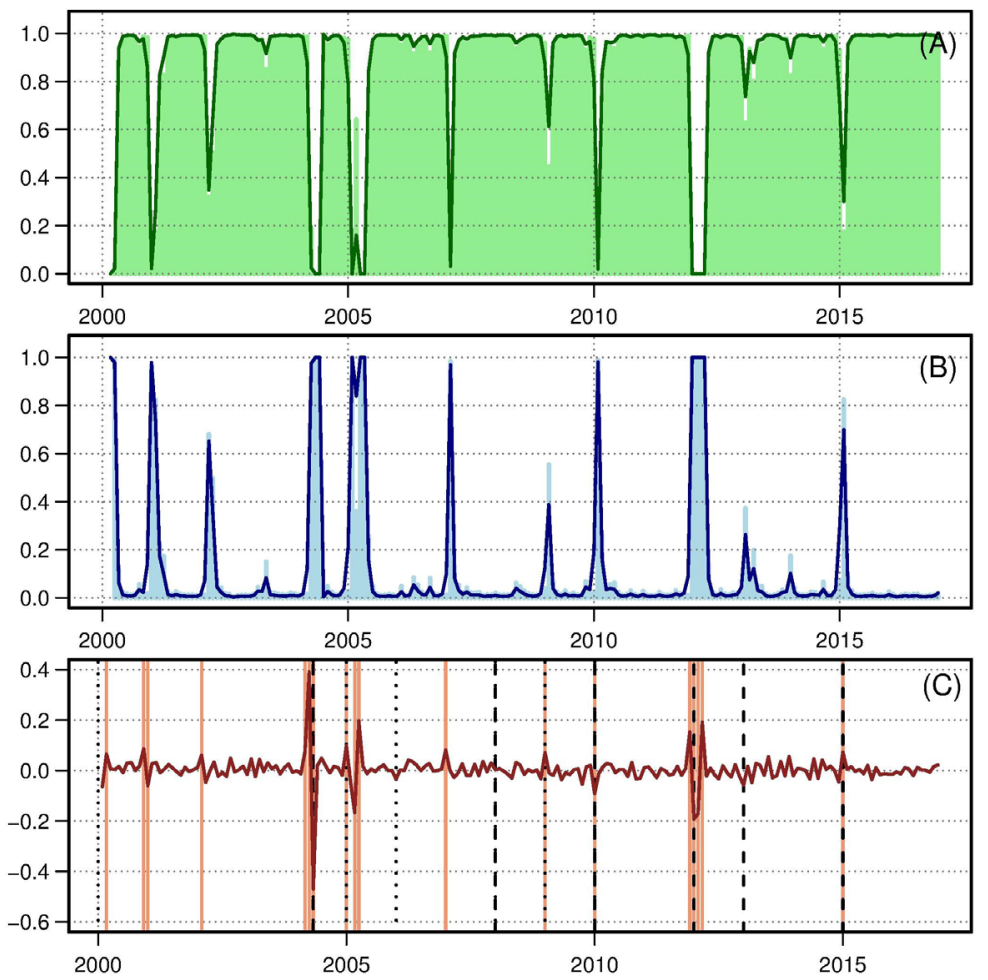

4: Filtered and smoothed probabilities of observations classified in regime 1 (A); filtered and smoothed probabilities of observations classified in regime 2 (B); observation membership in regime 2 (full red line) and effective dates of VAT (dashed line) or CT (dotted line) tax code amendments (C).

\section{CONCLUSIONS}

In this study, we applied a two-state Markov-Switching model to monthly construction sector output in the Czech Republic after necessary adjustments and transformation to natural logs of gross returns. The role of the Markov-Switching model is focused mainly at description, significance testing and data classification in regimes; forecasting future observations is not valuable nor accessible in econometric software. We found evidence, that the response variable shows dissimilar behavior in the model's two regimes. In the first regime of common performance, the construction output displays regular dynamics combined with naturally low variation, while in the second regime; the level of the output and its variation are obviously lifted. The second regime is often located in periods at the beginning or the end of the calendar year and its relative impact upon the cumulated construction output may be limited, since $<10 \%$ data have been classified in the second regime. In the first regime, the construction output is negatively influenced by precipitation, as would be anticipated in large outdoor projects. In the second regime, conversely, ambient temperatures positively affect the construction sector performance, however the model fit in the second state is substantially better.

The estimated transition probability matrix suggests that between neighboring observations of the time series a change from State 1 to State 2 is uneasy to occur. However, once the second regime was established, is endures or changes to Regime 1 with about equal probability. Classification of the observed data in the second regime is often tied to macroeconomic events that exert influence upon the construction sector and occurs in the period close to season holidays. All in all, it's primarily the effective dates for changes of the country's tax system related both to the Value Added Tax and the Corporate Tax rates that often overlap with dating of the observations in the model second state. Contracts in the construction sector often include fixed prices for completed projects that were agreed upon many years ago. An upward change of the tax rates then tends to shrink the building company margins. Although the companies show efforts to realize the most of the contract under favorable tax conditions, even with resources stretched to the limit, the loss in revenues for the state may not be significant and if any, it may be recouped in the following period. Apart from the macro events, it is the political cycle and EU funding periods that often affect the launch of major infrastructure projects and contribute significantly to the Czech construction sector output. The author is nonetheless aware, that conclusions presented above are mainly pertinent to situations with tax rate increase and that asymmetric response of the construction sector is probable to occur for scenarios with tax rate cut. 


\section{REFERENCES}

ARLT, J. and ARLTOVÁ, M. 2007. Ekonomickéčasové ŕady. $1^{\text {st }}$ Edition. Praha: Grada Publishing, a.s.

BROCKWELL, P. J. and DAVIS, R. A. 1991. Time series: theory and methods. $2^{\text {nd }}$ Edition. Berlin: Springer Verlag. CLEVELAND, R. B., CLEVELAND, W.S., MCRAE, J. E. and TERPENNING, I. 1990. STL: A seasonal-trend decomposition procedure based on Loess. Journal of Official Statistics, 6(3): 3-73.

CUŘINOVÁ, P. 2016. Stavebnictví v regionech ČR. Statistika a My, 6: 14-15.

DEMPSTER, A. P., LAIRD, N. M. and RUBIN, D. B. 1977. Maximum likelihood from incomplete data via the EM algorithm. Journal of Royal Statistical Society, 39(1): 1-38.

DICKEY, D. A. and FULLER, W. A. 1981. Likelihood ratio statistics for autoregressive time series with a unit root. Econometrica, 49(4): 1057-1071.

HAMILTON, J. D. 1990. Analysis of time series subject to changes in regime. Journal of Econometrics, 45(1-2): 39-70.

HAMILTON, J. D. 1994. Time series analysis. Princeton University Press.

KWIATKOWSKI, D., PHILLIPS, P. C. B., SCHMIDT, P., and SHIN, Y. 1992. Testing the null hypothesis of stationarity against the alternative of a unit root. Journal of Econometrics, 54: 159-178.

LÓPEZ-DE-LACALLE, J. 2013. Why Does the Expectation-Maximization Algorithm Converge Slowly in Pure Variance Structural Time Series Models? Unpublished manuscript.

MARAVALL, A., GÓMEZ, V. and CAPORELLO, G. 1996. Statistical and Econometrics Software: TRAMO and SEATS. Madrid: Banco de España.

MITRENGA, J. and BĚLOHLÂVEK, P. 2017. Stavební odvětví v ČR a jeho program dalšího rozvoje. ČKAIT. [Online]. Available at: http://www.ckait.cz/content/stavebni-odvetvi-v-cr-jeho-program-dalsiho-rozvoje [Accessed: 2018, January 25].

R DEVELOPMENT CORE TEAM. 2017. R: A language and environment for statistical computing. Vienna, Austria: R Foundation for Statistical Computing.

SANCHEZ-ESPIGARES, J. A. and LOPEZ-MORENO, A. 2014. MSwM: fitting Markov switching models. $\mathrm{R}$ ackage version 1.2. Available at: https://cran.r-project.org/package=MSwM [Accessed: 2018, May 15].

SAX, C. 2016. Seasonal: R Interface to X-13-ARIMA-SEATS. R package version 1.3.0. https://cran.r-project.org/ package=seasonal [Accessed: 2018, May 15].

ZIVOT, E., and WANG, J. 2006. Modeling financial time series with S-Plus. $2^{\text {nd }}$ Edition. Berlin: Springer Verlag. 